\title{
Study and Practice of Flipped Classroom under the Concept of CDIO
}

\author{
Songping Chen \\ School of Tan Kah Kee College Xiamen University, Zhangzhou 363105, China \\ send_me@126.com
}

\begin{abstract}
The CDIO engineering education concept is applied to the Numerical Control Technology and Application for the curriculum reform, and then is employed to practice teaching reform by combining with the flipped classroom, to achieve effective teaching a student-centered "Learning by Doing". It is effective against encouraging the students to be initiative in learning, meeting the needs of individual learning, and enhance the students' ability in practice and consciousness of engineering. Combines knowledge teaching, capacity-building and quality education in one. Provide ideas of Engineering teaching reform under the new situation, this also provides a reference to the cultivating pattern of applicative and innovative talents in university.
\end{abstract}

Keywords: CDIO; flipped classroom; numerical control; effective teaching.

\section{CDI0理念下的翻转课堂教学研究与实践}

\section{陈松平 \\ 厦门大学嘉庚学院, 漳州 中国}

摘 要: 将CDI0工程教育理念应用于 “数控技术及应用” 课程改革中, 结合翻转课堂进行教学 改革实践, 实现了以学生为中心 “做中学” 的有效教学。有效地激励了学生的自主学习意识, 满足了个性化的学习需求, 提高了学生实践能力和工程意识。融知识传授、能力培养和素质 教育全面协调发展, 为新形势下工科课程教学改革提供思路, 也为高校应用创新型人才培养 提供参考。

关键词: 关CDI0; 翻转课堂; 数控; 有效教学

\section{1. 前言}

CDIO 即构思一设计一实施一运行, 是以项目为引导, 以工程项目从研发到运行的全生命 周期为载体, 让学生以主动的、实践的、课程之间有机联系的方式学习工程的理论、技术与 经验的工程教育模式 ${ }^{[1]}$ 。国内外许多高校以 CDI0 工程教育理念为基础进行工程教育探索和改 革，取得良好的效果，它高度概括和体现了 “做” 中 “学”、“学” 中“做” 以及项目化教 育教学, 让学生通过工程项目从研发到运行以主动的、实践的、课程之间有机联系的方式学 习工程, 尤其是项目组织、设计、开发和实施能力, 以及较强的沟通能力和协调能力, 体现了 当今工程教育的国际共识。翻转课堂教学模式以 “学” 为主、“教” 为辅, 将课前、课中和 课后有效结合, 开展 “以学生为中心” 的学习活动, 同时充分发挥教师的主导作用 ${ }^{[2]}$ 。数控 技术及应用是一门专业主干课程, 实践性强, 将 CDIO 工程教育理念融入课程中, 并采用翻转 课堂教学法, 真正做到以学生为中心 “做中学”、“学中做”、“做中思” 和 “思中创” 的 有效教学。 


\section{2. 融合CDIO 理念的翻转课堂教学实施}

\section{1. 数控技术及应用课程教学现状}

数控技术及应用课程内容涉及到数控加工与程序编制、数控装置、数控伺服系统、检测装 置和机械结构等内容, 目前高校大多采用以集体教学为基础, 强调 “听中学” 的传统教学模 式, 教师决定着教学的方向和内容, 掌握着教学目标和教学进度, 没有留给学生独立思考的 时间和空间, 处于一个被动接受知识的地位, 对课程内容的学习、理解程度还不够深入, 导 致学生被动地接受知识, 缺乏举一反三的能力。这样教师辅之以个别化帮助也因课堂时间受 限, 抑制了学生主动学习的积极性, 再加上学生个体差异的存在, 直接导致了部分学生掉队。 另一方面由于教学课时的限制, 学生实践也以验证型实验为主, 很难有机会进行综合型实验, 更谈不上实际的工程应用, 从而造成学生在动手能力、主动学习能力、创新能力不强等, 不 利于应用创新型人才的培养。

2.2. 基于 CDIO 的翻转课堂教学模式的设计与实施

2.2.1教学模式的提出

CDI0 核心思想是强调学生的综合创新精神与创新能力, 尤其注重学生工程实践能力、产 品设计能力, 注重团队成员之间相互探讨、交流、协作，共同完成项目设计、规划，最后独 立实施完成项目。这样的学习模式, 学生是中心, 有一个明确的项目, 在项目实施过程中, 教师、实验技术人员会经常检查、督促项目进度, 给予指导, 帮助学生完成项目。而翻转课 堂教学模式中, 将传统的学习过程中的知识传授和知识内化这两个阶段进行颠倒, 即学生课 前通过教学视频、教学资料完成知识的传授, 而课堂中学生通过分组讨论、习题、难点答疑 等多种教学形式实现知识的内化 ${ }^{[3]}$ 。从二者的比较中可以看到, CDI0 工程教育模式和翻转课 堂教学模式相辅相成, 都是将课堂还给学生, 都是从学生的知识、技能、态度三方面培养学 生就业的竞争力, 体现了高效率和优效果的能力培养模式。因此, 本文提出了将 CDI0 工程教 育理念与翻转课堂教学模式的融合的思路, 即在教学过程中, 将教学内容项目化, 按 CDI0 理 念组织教学过程, 按翻转课堂方式组织教学活动。

\subsection{2教学模式的设计}

基于 CDI0 的翻转课堂教学法要求教学内容要选择真实性项目为载体, 以任务为驱动, 以 符合学生的认知规律和职业成长规律来设计课程知识点体系。依据 CDIO 理念的 12 条标准, 创新应用型人才培养应重视学生职业基本能力、个人拓展能力、团队协作能力和职业素质能 力的培养 ${ }^{[4]}$ 。实现这一目标的有效手段是以项目为导向, 通过各级不同的项目将整个课程体 系有机地结合起来。具体思路是: 依据数控技术及应用教学大纲, 将需要学习和掌握的专业 知识围绕项目训练这个核心展开，并与这个核心融合在一起，形成一个有机整体。项目任务 按照 CDIO 的四个阶段来开展, 即构思、设计、实施和运作, 也就是产品从研发到运行的生命 周期。由此形成了如图 1 所示的 “三项目、四个阶段” 的教学模式。

\begin{tabular}{|c|c|c|c|c|c|}
\hline 课前：录制基础视频布置基础项目 & & & & & 棵前: 发布学习心得模版 \\
\hline 课中: 总结知识答疑辅导检则评价 & ○教师 & & & 教师 @ & 课中: 辅导检测答疑评价总结反思 \\
\hline 课后: 辅导答疑总结反思 & & & & & 课后: 总结交流完善教学 \\
\hline 课前：观看基础视频完成基础项目 & & 构思 (C) & 运作 $(0)$ & & 课前：填写学习心得 \\
\hline 课中: 展示交流基础项目成果构思 & 。 学生 & & & 学生 of & 课中: 展示各级项目交流心得 \\
\hline 课后：完成基础项目达标项目选题 & & & & & 课后: 将技能应用于实训实践中 \\
\hline & & & & & \\
\hline 课前: 录制达标视频设计项目文档 & & & & & 课前: 录制拓展视频布置拓展项目 \\
\hline 课中: 展示设计文档䊇导笞疑评价 & ○ 教师 & & & 教师 $\mathrm{O}$ & 课中: 辅导检测答疑评价总结反思 \\
\hline 课后: 辅导管疑总结反思 & & & & & 课后: 辅导笞疑总结反思 \\
\hline 课前：观看达标视频填写设计文档 & & 设计（D) & 实施（I） & & 课前：观看拓展视频尝试拓展项目 \\
\hline 课中: 展示达标成果交流达标设计 & 学生 & & & 学生 of & 课中：展示拓展项目成果交流讨论 \\
\hline 课后：完善达标项目完善设计文档 & & & & & 课后：完善拓展项目 \\
\hline
\end{tabular}

图1 CDIO理念下 “三项目、四个阶段”教学模式 


\subsection{3翻转课堂的实施}

通过翻转课堂的形式使学生的学习过程转变为学习探索、解释接受、领会应用三个阶段: 教师在课前（上课前一周内）共享教学视频等资源使学生在网络空间平台的答疑室、讨论区 实现平台交流; 课堂教学设计由课堂活动、知识点疑惑、训练、提交课堂成果等环节组成, 提升学生自主学习能力、独立探索能力; 课后知识固化环节要求学生进行知识点回顾、学习 总结, 有助于促进学习认知中各知识点之间的衔接与关联性, 注重培养学生的团结协作、应 用能力。具体的实施分为课前、课中和课后三个过程, 如图 2 所示, 课前环节构成要素有教 师制作教学微视频、教师设计课前自主学任务单、学生观看教学微视频、学生完成课前自主 学任务单、学生标记疑惑提出问题等。课中分理论课和实践课, 理论课主要是学习内容热身、 小组协作学习、学习成果展示与交流。实训课则由学生自主实现各级任务, 教师辅导答疑和 评价反馈等。课后主要有学生制作作品、学生分享作品、教师评价作品、学生互评作品、期 末考试等要素构成。本部分选取课程中的数控加工的程序编制部分作为应用案例。该部分要 求学生掌握数控车床、铣床和加工中心程序的编制方法, 并能应用计算机辅助编程。根据教 学目标, 教师将数控车床编程部分的基础项目设计为加工一件 45 钢材料工艺轴, 达标项目为 加工二级减速器传动轴, 拓展项目则为数控车工技师技能鉴定考核题, 由浅入深、循序渐进, 使学生始终感到有能力完成项目, 激发学生挑战项目的欲望。每级项目都结合一个具体的零 件, 把项目任务布置给学生, 在构思阶段, 要求学生熟悉项目任务、明确工作内容、查阅相 关资料并讨论加工方案; 在设计阶段, 要求学生设计整个零件的加工方案, 如制订加工工艺 方案（包括毛坏准备、机床选择、确定工艺参数、工装夹具、刀具、量具选择等）、填写工 艺卡和工序卡、编写加工程序等; 在实施阶段, 要求同学根据编制的零件加工程序, 经数控 仿真软件模拟加工后, 再到实物机床上进行加工, 并通过量具给出测量报告; 运作阶段则通 过学生的自评、互评和教师点评等, 对整个工作学习过程进行分析评价、总结经验、改进不 足之处。

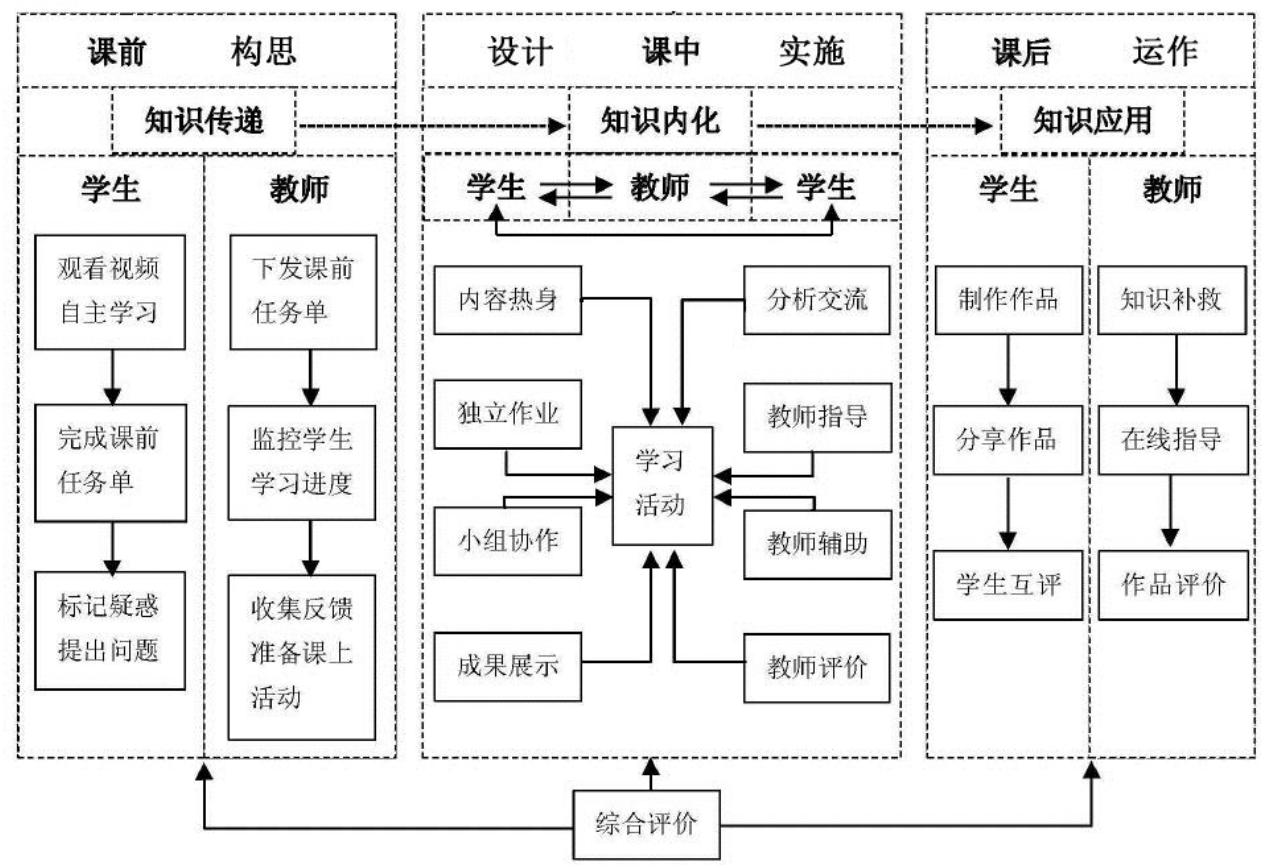

图2 CDIO理念下的翻转课堂教学模式

\subsection{4建立多元化的课程评价策略}

基于 CDIO 工程教育理念下的翻转课堂教学 评价体系的构建一般既要注重教学过程与学 习成效并重, 也要符合多元化发展原则 ${ }^{[5]}$ 。传统的课堂教学是由任课教师来考评学生, 重在 知识的获得, 对教学过程的关注不够。而基于 CDIO 翻转课堂教学质量的评价体系则重在能 力培养, 能力本位的教学观贯穿课程设置和教学实践的全过程, 注重从评价材料、评价主体 等方面的多元化发展。因此必须确保能力评价过程的合理性和有效性, 采用不同的方法评价 
不同的能力。以数控加工程序编制模块为例, 建立如图 3 所示的课程多元化评价策略, 学生 各自完成作业, 除了接受自我评价和相互之间的评价外, 还需接受老师、考评员或企业工程 师等多个评价主题的评价, 学生能够发现和认识自我不足, 激发学生学习热情。这样的评价 体系从课前的案例构思、课中的设计和实施到课后的运作四个层面对学生学习全过程进行评 估, 改变以期末卷面考试为主要评价依据的评价方式, 逐步完善知识+技能+态度的考核方式。 模拟企业项目开发团队组建学习协作小组, 采取项目负责人制度, 负责本小组的任务分配、 进度跟踪、质量监控。项目完成后, 通过展示成果、学生互评、教师评价, 深化了学习成果, 提高了沟通能力。

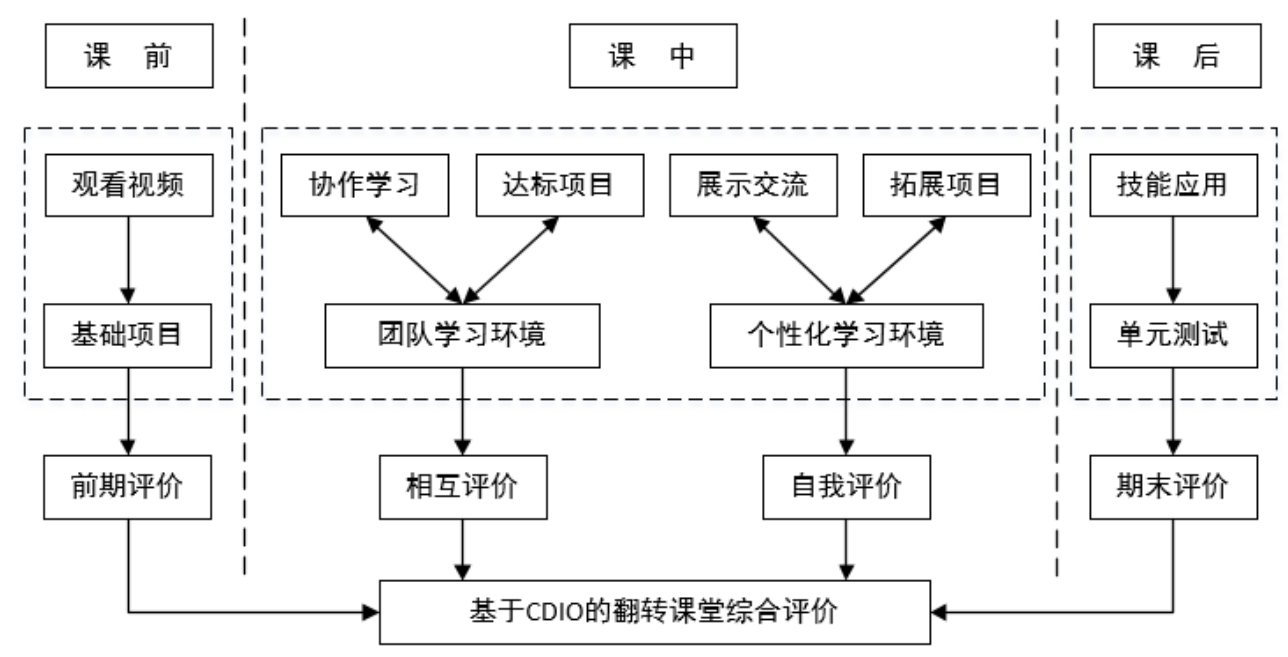

图3 课程多元化评价策略

\section{3. 结论}

将 CDIO 工程教育理念融入到数控技术及应用课程中，积极尝试 “三级项目、四个阶段” 的翻转课堂教学模式授课, 实现了以学生为中心 “做中学”、“学中做”、“做中思” 和 “思 中创” 的有效教学, 不仅提高了学生自主学习的积极性, 锻炼了自主创新能力, 也培养了学 生的团队协作、职业道德和职业素养。

\section{致谢}

感谢 “福建省中青年教师教育科研项目资助（项目编号：JAS150774）”基金。

\section{References}

[1] Yongfang Tao, Cunhui Shang. Inspiration CDIO Syllabus for Higher Engineering Education Innovation. China Higher Education Research. Vol. 5 (2006) No. 11, p. 81-83.

[2] Yi Chen, Chengling Zhao. An Instructional Design and Application Research Based on the Flipped Classroom Model. Modern Educational Technology. Vol. 3 (2014) No. 2, p. 49-54.

[3] Xiaofei Chen: Study on the Flipped Classroom Model (Master's degree, Central China Normal University, China 2014). P.1-59.

[4] Yuefei Li. Analysis on the mechanism of the effect of the flipped classroom teaching based on the CDIO. Western China Quality Education. Vol. 4 (2015) No. 11, p. 36-38.

[5] Jianzhong Zha. Engineering Education Reform Strategy "CDIO" and the Cooperation and Internationalization of Production. China University Teaching, Vol. 6 (2008) No. 5, p.16-19. 